\title{
The effect of texture on the low cycle fatigue property of Inconel 718 by selective laser melting
}

\author{
Zhongjiao Zhou, Xu Hua, Changpeng Li, Guofeng Chen* \\ Materials \& Manufacturing Qualification Group, Corporate Technology, Siemens Ltd., China, Beijing 100102, China
}

\begin{abstract}
In recent decades, additive manufacturing (AM) technology has shown its great advantages to produce end-use products with complex design and high-added value. However, the AM-specific characters, such as inherent material anomalies (porosity, lack of fusion defects, or inclusions), anisotropy, location-specific properties and residual stresses, prevent AM from widely adoption in safety-critical parts. Therefore, the damage tolerance assessment of AM parts is desperately necessary. In this study, the impact of residual stress and the induced texture (columnar/equiax grain structure) after different heat treatment on the low cycle fatigue (LCF) behavior of Inconel 718 fabricated through selective laser melting (SLM) is investigated. The results showed that the texture of AMed parts can be controlled by suitable heat treatment, based on the residual stress during AM processing acting as the drive force to recrystallization. For SLMed Inconel 718 samples with columnar grains, anisotropic LCF properties exist, while no obvious sensitivity to orientations is shown for samples with equiaxed grains. This work is significantly meaningful to speed up the design-to-product transformation of safety-critical AM parts and optimize the orientation of components for various applications.
\end{abstract}

\section{Introduction}

Additive manufacturing (AM) technique has already been known for more than 20 years, but it experiences considerable publicity and growth in the past few years due to its great advantages to produce end-use products with complex design and high-added value. Currently, most of successful cases of AM are for non-missioncritical applications, in which the microstructure and monotonic response of alloy are studied. However, to meet the full potential that AM has to offer, especially for safety-critical components (e.g., rotating parts, fracture-critical parts, etc.), the qualification considering creep and fatigue testing are necessary [1].

Inconel 718 is the most utilized superalloy for aerospace application, high temperature plants and cryogenic systems due to its low price/performance ratio, good formability and weldability properties [2]. Inconel 718 belongs to the class of precipitate strengthened $\mathrm{Ni}$ base superalloys, with the primary strengthening phase being $\gamma^{\prime \prime}$ with a minority $\gamma^{\prime} \square$ that may co-precipitate with the $\gamma$ ". The good weldability makes Inconel 718 ideally suited for the investigation of SLM process [3].

During AM processing, due to the rapid heating of the upper surface by the fast moving heat source (laser in present study) and the relatively slow heat conduction, a steep temperature gradient develops. Then the expansion of the heated top layer is restricted by the underlying material, thus forming residual stress during processing [4]. If the residual stress is high enough, it may cause the distortion and even failure of AMed parts. In the case that the residual stress is relatively low, it may act as the drive force to recrystallization during the following heat treatment. The recrystallization will break the wellknown columnar-grained structure of as-built AMed parts, thus influencing the mechanical properties.

Many work have been reported to control the texture for AMed parts [5-8]. Dinda et al. [5] were the first to report on the ability to steer the growth direction of grains through changing the direction of the laser heat source. Later, Dehoff et al. [6] demonstrated the premise of texture control within AM materials in a site-specific manner in the electron beam melting (EBM) process, through manipulation of the thermal conditions within the melt pool in the different regions, although not in a perfect manner. Recently, Helmer et al. [7, 8] have shown the ability to influence the grain structure in the EBM process for Inconel 718 through changing the parameters associated with the standard raster scan strategy utilized by the process.

However, based on the black box algorithm of the AM process, applying texture control over generic crosssections within bulk structures in a controlled manner is extremely challenging. A relatively simple and easy to implement method is needed for texture control. In addition, the influence of various texture on the mechanical properties of AMed parts is not very clear.

As mentioned above, due to the nature of fast melting and solidification, residual stress is inevitable during AM processing. The goal of this work is to control texture by subsequent heat treatment, in which different degree of recrystallization occurs drived by 
residual stress. Afterwards, the influence of textures on low cycle fatigue properties of SLMed Inconel 718 is studied.

\section{Materials and experimental}

Commercial Inconel 718 powders with an average particle size of 20 to $50 \mu \mathrm{m}$ were used as the feedstock materials in present experiments. The manufacturing of the samples was performed in an EOSINT M280 machine operated at a power of $\sim 285 \mathrm{~W}$ with a scanning speed of $0.96 \mathrm{~m} / \mathrm{s}$, laser focus spot size of $70 \mu \mathrm{m}$, and laser thickness of $40 \mu \mathrm{m}$, under an argon atmosphere with an oxygen level of $0.01 \%$. The scanning strategies was bidirectional scanning with a rotation of $90^{\circ}$ between layers (Scan Strategy YX) that repeats the Y scan and X-scan (as shown in Fig. 1a).

Then, two heat treatment methods were applied to obtained different textures:

1. SA (Solution + double ageing): solution at $980{ }^{\circ} \mathrm{C} / 1 \mathrm{~h}, \mathrm{AC}+$ double aging at $760{ }^{\circ} \mathrm{C} / 10 \mathrm{~h}$, furnace cooling for $2 \mathrm{~h}$ to $650{ }^{\circ} \mathrm{C}$ and holding at $650^{\circ} \mathrm{C} / 8 \mathrm{~h}, \mathrm{AC}$

2. HA (homogenization + double ageing): homogenization at $1065{ }^{\circ} \mathrm{C} / 1 \mathrm{~h}, \mathrm{AC}+$ double aging at $760{ }^{\circ} \mathrm{C} / 10 \mathrm{~h}$, furnace cooling for $2 \mathrm{~h}$ to $650{ }^{\circ} \mathrm{C}$ and holding at $650{ }^{\circ} \mathrm{C} / 8 \mathrm{~h}, \mathrm{AC}$.

To investigate the microstructure, the AMed samples were mechanically polished via a standard metallographic procedure using $1 \mu \mathrm{m}$ diamond powder in the final stage of polishing. After final electropolishing the specimen was etched in a solution composed of $70 \mathrm{vol} \% \mathrm{H}_{3} \mathrm{PO}_{4}$ and $30 \mathrm{vol} \% \mathrm{H}_{2} \mathrm{O}$ at $5 \mathrm{~V}$ at room temperature. The texture was taken using an electron backscatter diffraction (EBSD) system mounted on a field-emission scanning electron microscope (FESEM; Supra 35; Zeiss; Germany). An X-ray CT was utilized as non-destructive measuring technique for internal porosity detection due to its capability of providing a complete analysis of size, shape, volume and distribution of pores/defects within the entire analyzed volume.

After microstructural characterization, low cycle fatigue (LCF) experiments were performed. The LCF testing was performed on cylindrical dog-bone specimens, with printing orientation and size of LCF samples shown in Fig. 1. To examine the influence of anisotropy of the SLMed In718 material, the loading axis of the different samples was oriented parallel and transverse to the build direction. All LCF experiments were conducted under strain-controlled conditions, with $\mathrm{R}=-1$ at $650{ }^{\circ} \mathrm{C}$ and strain amplitude of $0.40 \%$ (Fig. 1c).
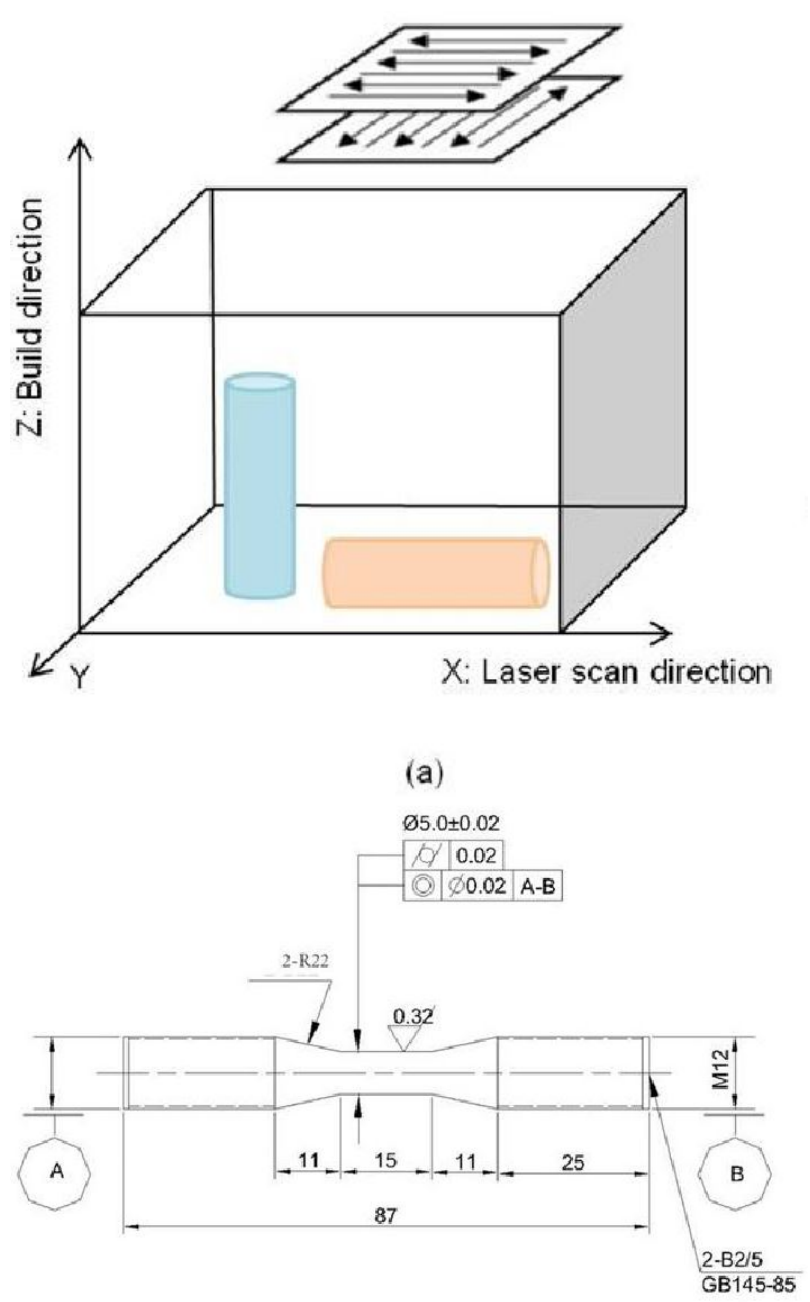

(b)

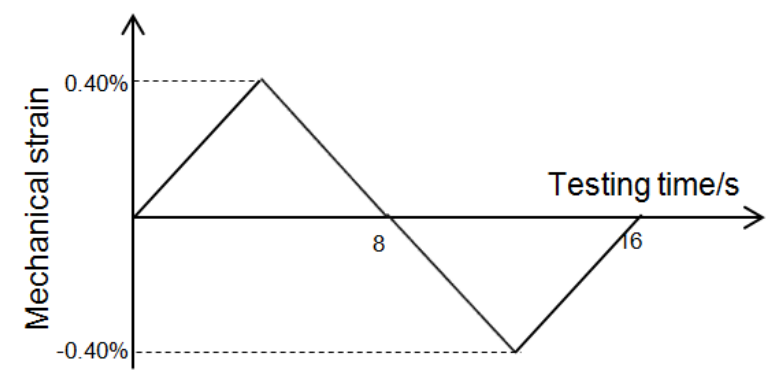

(c)

Fig. 1. The schematic of sample orientation (a), LCF testing sample (b) and the LCF testing condition (c).

\section{Results and Discussion}

The resultant textures of as-built SLMed Inconel 718 are illustrated in Fig. 2. Obviously, the standard linear heat source resulted in a columnar grain with orientation of $\langle 001\rangle$ and $\langle 110\rangle$ aligned parallel to the build direction (Fig. 2a). However, in the plane transverse to the building direction, equiaxed grains rather than columnar grains were observed (Fig2. b). Most of these 
columnar grains showed $3 \mu \mathrm{m}$ in widths and $18.5 \mathrm{~mm}$ in length (Fig2. c).
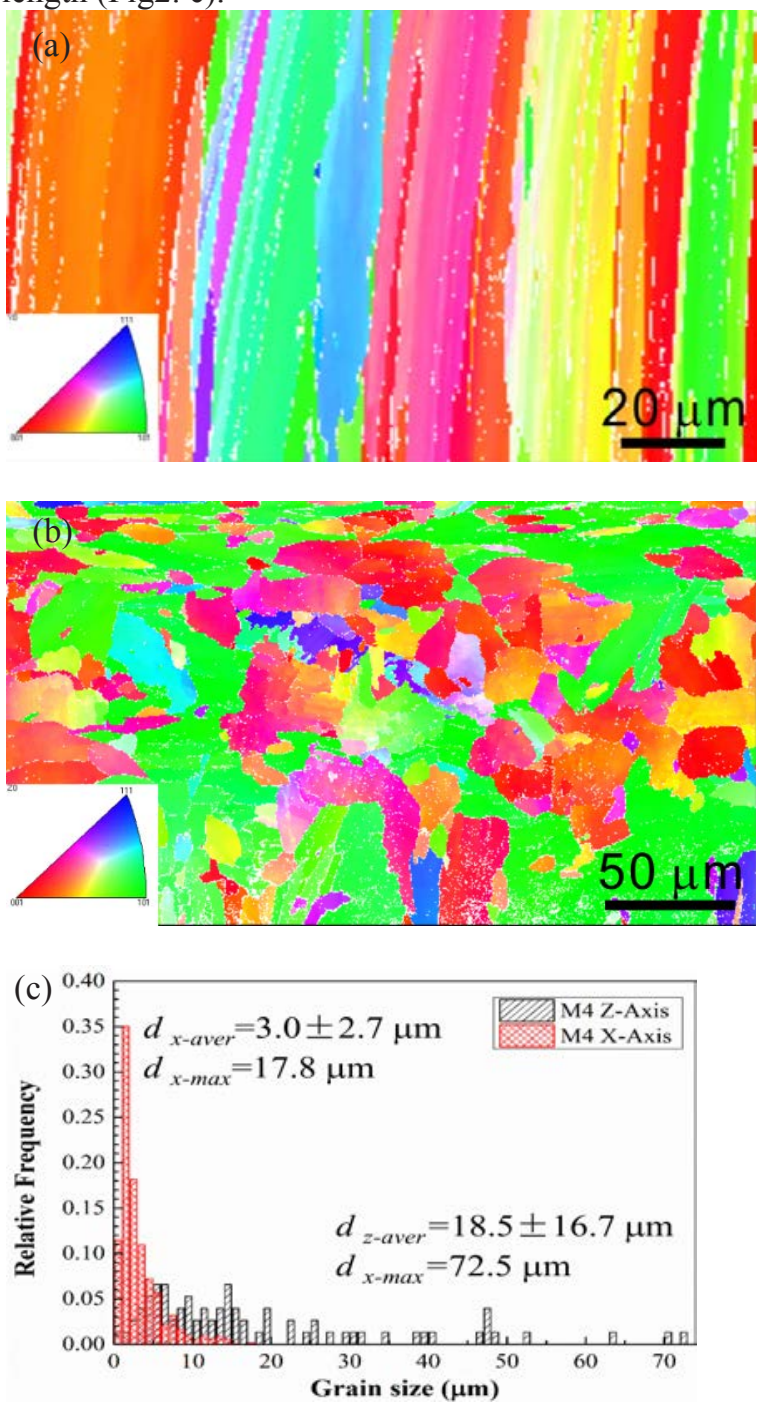

Fig. 2. EBSD analysis depicting the texture on the plane parallel to the building direction (a), on the plane transverse to the building direction (b) and the grain size distribution of columnar grains (c).

The pore distribution analyzed by X-ray CT is shown in Fig. 3. The density is about $99.85 \%$ with the largest pore with diameter $40 \mathrm{~mm}$. three types of pores were observed: Large irregular pores caused by a lack of melting, shrinkage micropores due to a lack of feeding within interdendritic zones and spherical pores caused by trapped gas.

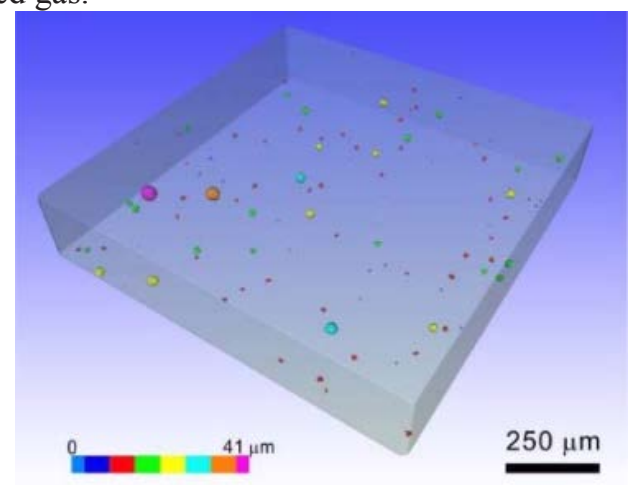

Fig. 3. The CT reconstructed 3D volume of SLMed In718 showing the pores/defects distribution

After heat treatment, different degree of recrystallization occurred which was drove by the residual stress during AM process, leading to different textures, as shown in Fig. 4. As for SA samples, only partly recrystallization occurred and the columnar grains still existed parallel to the build direction (Fig. 4a). However, as for the HA samples, fully recrystallization occurred and all the columnar grained had transformed to equiaxed grains, as shown in Fig. $4 \mathrm{~b}$.
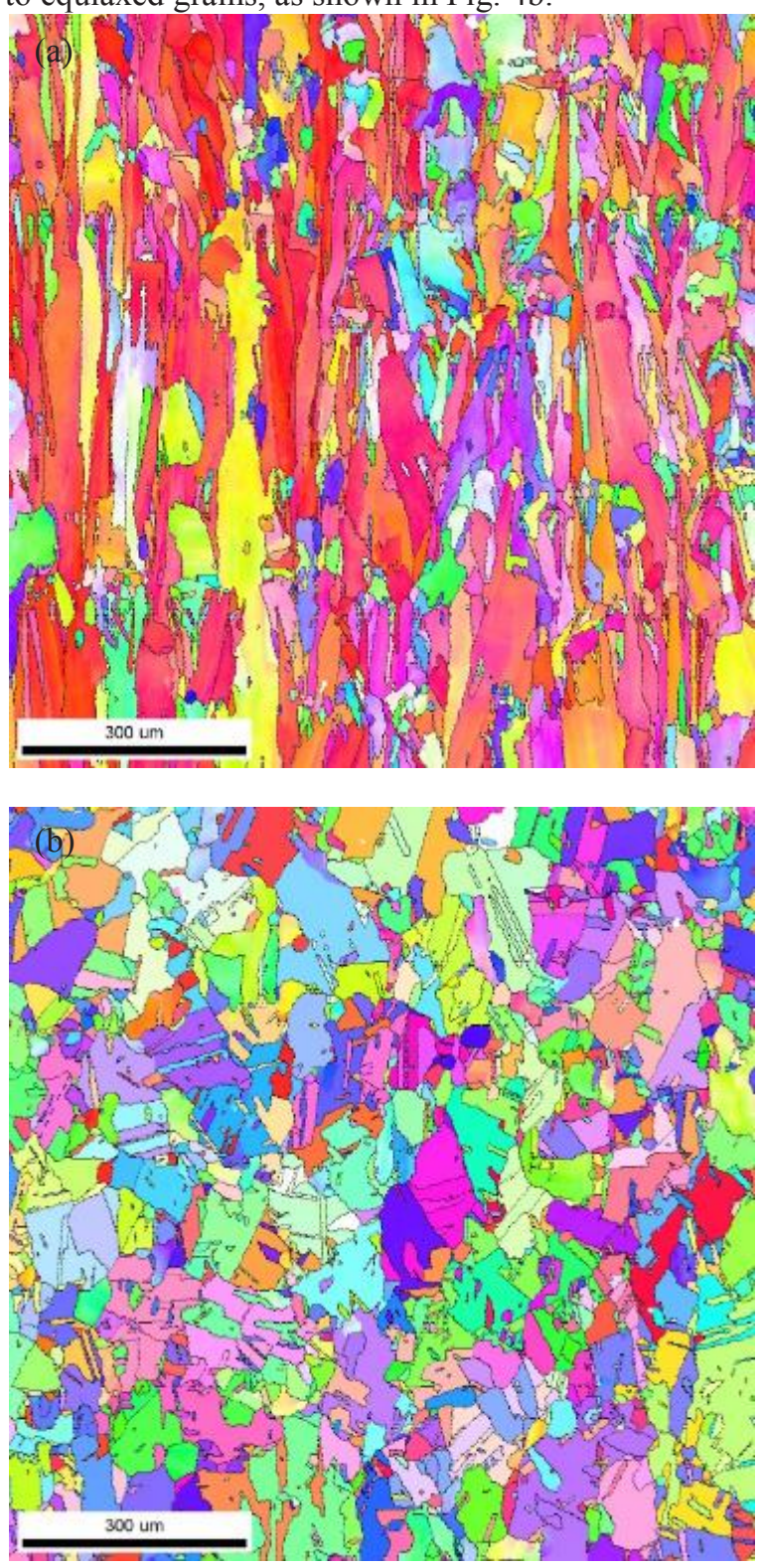

Fig. 4. The EBSD results of SA sample (a) and HA sample (b).

The textures have a significant influence on the LCF life, as shown in Fig. 5. Obvious anisotropy exhibited for samples with columnar grains. Amongst the textures, the columnar grains oriented parallel to the build direction exhibited the highest life on average compared to the transverse columnar material. However, for samples with equiaxed grains, the samples parallel to the building direction showed comparable LCF life to those 
transverse to the building direction, namely the mechanical anisotropy nearly disappeared.

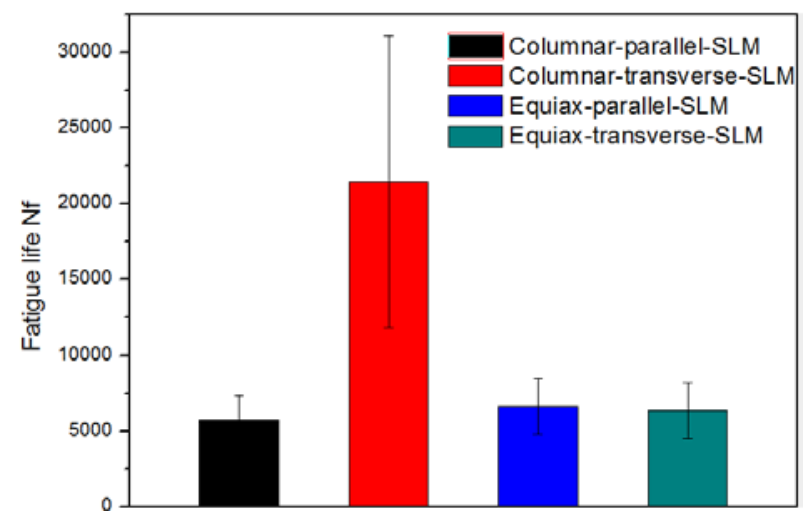

Fig. 5. The LCF life of samples with different textures

Based on the cyclic stress amplitude for each material orientation and texture, the material achieved stabilized hysteresis within the first few initial cycles as illustrated in Fig. 6. The HA sample, namely samples with equiaxed grains showed higher cyclic stress amplitude compared to the SA samples with columnar grain, which may be attributed to the cyclic Young Modulus in various texture orientation.

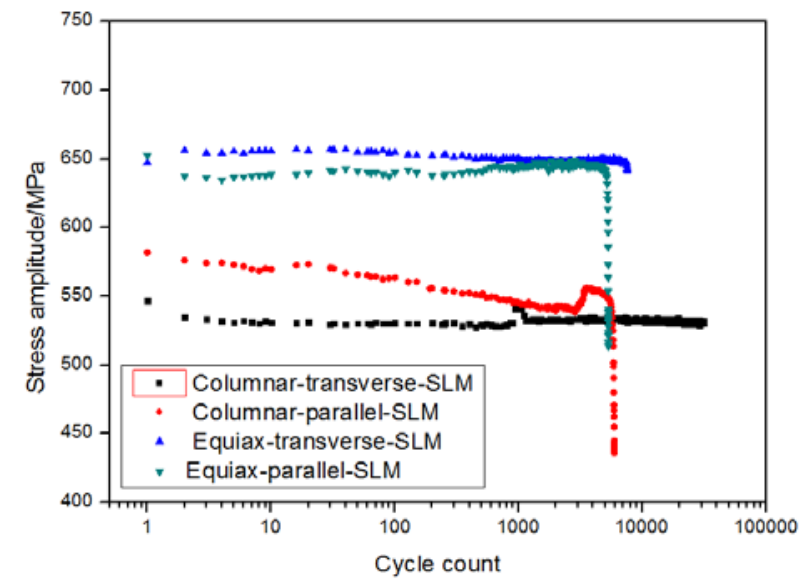

Fig. 6. Comparison of stress amplitude for samples with different textures.

Generally, various textures are desired for different applications based on the loading condition and property requirement. Just as investment casted turbine blades for aerospace application, the low Young Modulus <100> single crystal or columnar orientation is preferred to obtain lower stress parallel to the growth direction of blades, while equiaxed and small grains are needed for turbine disks to ensure longer lifetime. With the development of AM techniques, the texture control will be required; especially for AMed parts whose creep or fatigue properties are required.

The present work has illustrated the possibility to control texture of AMed parts by suitable heat treatment utilizing the residual stress during AM processing. In further study, the quantitative characterization of residual stress as well as the relationship between the residual stress and solution temperature need to be investigated, which will be significantly meaningful to speed up the design-to-product transformation of AMed parts and optimize the orientation of components for various applications.

\section{Conclusion}

In this work, the effect of textures and material anisotropy on the low cycle fatigue behavior of SLMed Inconel 718 was examined at $650{ }^{\circ} \mathrm{C}$. The following conclusions can be obtained:

1. Based on the residual stress during $\mathrm{AM}$ processing acting as the drive force to recrystallization, the texture of AMed parts can be controlled by suitable heat treatment.

2. For SLMed Inconel 718 samples with columnar grains, anisotropic LCF properties exist and the columnar grains oriented parallel to the build direction exhibited the highest life.

3. For SLMed Inconel 718 samples with equiaxed grains, no obvious sensitivity to orientations is shown.

\section{References}

1. M. Seifi, A. Salem, J. Beuth, O. Harrysson, J.J. Lewandowski, JOM, 68, 3 (2016)

2. C. Sims, The Superalloys, John Wiley and Sons, (1972)

3. P. Blackwell, J Mater Process Technol, 170, 240 (2005)

4. B. Cheng, K. Chou, 25th Annual International Solid Freeform Fabrication Symposium - An Additive Manufacturing Conference, 1076 (2014)

5. G. Dinda, A. Dasgupta, J. Mazumder, Scr. Mater. 67, 503 (2012).

6. R.R. Dehoff, M.M. Kirka, W.J. Sames, H. Bilheux, A.S. Tremsin, L.E. Lowe, S.S Babu, Mater. Sci. Technol. 31, 931 (2015).

7. H.E. Helmer, C. Körner, R.F. Singer, J. Mater. Res. 29, 1987 (2014).

8. H. Helmer, A. Bauereiß, R.F. Singer, C. Ko“rner, Mater. Sci. Eng. A 668, 180 (2016). 